\title{
Roleplaying game como ferramenta de intervenção psicológica em grupo operativo
}

\author{
Roleplaying game as a psychological intervention tool in operative group
}

\section{Luísa Fialho da Silva' e Letícia Wilke Franco Martins}

Resumo: $O$ presente artigo consiste em um relato de experiência em Estágio Básico de Psicologia, que ocorreu em um grupo terapêutico em uma ONG de Porto Alegre-RS, Brasil. Realizou-se um Grupo Operativo (Pichón-Riviere) com quatro adolescentes cuja demanda identificada transpassava a fase do desenvolvimento vital do grupo, na qual a principal tarefa é a busca pela identidade, focalizando a identidade profissional. Observou-se o enfrentamento de problemas existenciais e a conquista de uma adaptação ativa às demandas da fase vital em que se encontravam. Este processo se deu por meio da fantasia e aprendizagem criativa perante a tarefa, sendo que o estado de tarefa grupal foi alcançado com a realização de Roleplaying Game. Durante o jogo, o grupo percorreu os seis vetores que sinalizam as transformações ocorridas no processo grupal. O grupo fez um salto de estado: de pré-tarefa para tarefa. Após, elaborou o projeto na tarefa. Evidenciou-se que o uso do jogo de interpretação de papéis facilitou este movimento por ser de categoria múltipla e envolver a criação de um avatar, que consequentemente favoreceu a projeção e identificação dos participantes bem como a revelação das fantasias universais, fundamentais para que 0 processo de mudança aconteça.

Palavras-chave: Adolescência; Grupo operativo; Processo grupal.
Abstract: This article is an experience report of Basic Psychology Internship, which occurred in a therapeutic group in a Non-Governmental Organization in Porto Alegre-RS, Brazil. An Operative Group (Pichón-Riviere) was carried out with four teenagers, whose identified demand went beyond the group vital development phase, which the main task is the search for identity, focusing on professional identity. There was observed the confrontation of existential problems and the achievement of an active adaptation to the demands of the vital phase that they found themselves. This process ocurred through fantasy and creative learning towards the task, and the group task state occurred by a Roleplaying Game. During the game, the group went through six vectors that mean how transformations occurred in the group process. The group made a leap from pre-task to task and then they made the project into the task. It was evident that the use of Roleplaying Game facilitated the movement as it has multiple categories and it involves the creation of an avatar, which consequently favored the projection and identification of participants as well as it showed universal fantasies that are necessary for the process of changing.

Keywords: Adolescence; Operative group; Group process.

\footnotetext{
1 Psicóloga. Realiza a Formação em psicoterapia psicanalítica do Espaço Vital (Gravataí, RS). E-mail: luisafialhosilva@gmail.com

2 Psicóloga. Especialista em Infância e Família (UFRGS). Mestra em Psicologia (UFRGS). Membro associado do ESIPP (Porto Alegre, RS). Coordenadora, docente e supervisora da Formação em psicoterapia psicanalítica do Espaço Vital (Gravataí, RS). E-mail: leticiafrancomartins@espacovitalgravatai.com.br
} 


\section{A adolescência}

Erikson (1972) associou o momento da adolescência à quinta crise da sua teoria psicossocial, denominada como Identidade X Confusão de papéis. Este momento vital tem como objetivo o autoconhecimento e reconhecimento do self. Nessa fase, 0 adolescente faz descobertas subsidiadas pelas suas próprias características, com o propósito de identificar-se junto ao grupo, e assim buscar a construção de sua identidade. Erikson configurou a identidade em três áreas principais de atuação: (1) Identidade Sexual; (2) Identidade Profissional; e (3) Identidade Ideológica (Erikson, 1972; Fiori, 2008; Lopes, Famoseli, Macedo, Figueiredo, \& Acácio, 2018).

Para Calligaris (2009), esta etapa da vida consiste em uma moratória imposta pela sociedade e destaca que culturalmente, no Brasil, é visto como adulto 0 indivíduo que se torna progressivamente independente. Assim, 0 adolescente sente-se frustrado pela moratória determinada, porém, a idealização social da adolescência espera que o indivíduo seja feliz, apesar das novas responsabilidades que assume.

0 adolescente busca apoiar-se nos modelos de referência que classifica adequados para uma autodefinição, o que dará direção de forma significativa no estabelecimento de apropriação da identidade. A atividade de reconhecer-se torna-se facilitada quando 0 adolescente é rodeado por pessoas que dispõem de personalidade bem definida, ideias claras e propósitos concretos. Compara-se a motivação necessária para o adolescente, ao efeito da torcida para os jogadores. Enfatiza-se que a aceitação ou falta de aceitação de sua existência e subjetividade influenciam no seu conceito de si e na disposiçãa necessária para atingir objetivos na vida (Lacerda \& Lacerda, 1998; Lopes et al., 2018).

A valorização das potencialidades do indivíduo faz com que o desenvolvimento das atividades que exerce se torne de qualidade mais elevada. Quando seu trabalho é compreendido, ele é estimulado em seu processo de construção da aprendizagem. Assim formam-se cidadãos que tomam atitudes perante as situaç̃ões, pensando e contribuindo na transformação da sociedade (Lacerda \& Lacerda, 1998). Visando o paradigma de Gardner, a adolescência é o período em que as inteligências se revelam, conduzindo o indivíduo na construção de sua identidade profissional e na sua identidade perante o grupo em que está inserido (Gardner, 2001),

A atuação profissional proporciona o sentimento de inserção social, a qual percebe-se uma ligação direta com a identidade pessoal. A identidade profissional se constitui como uma das principais tarefas da adolescência e é elaborada por meio da autopercepção e observação de modelos em que 0 indivíduo tem contato. Os grupos a qual 0 adolescente transita auxiliam na identificação de atividades laborais. A descoberta de características de personalidade influencia no processo de construção da identidade profissional, visto que esta caminha junto com a identidade sexual e ideológica. 0 adolescente pode experimentar atividades laborais que estejam de acordo com suas habilidades e interesses, considerando a identidade profissional não como algo definido, mas como um processo que abrange o contexto integral do indivíduo. A família tem papel importante como modelo e motivação de busca pela identidade profissional e no momento em que 0 adolescente não dispõe desses recursos na família, os grupos a qual transita se revelam de grande importância nesse processo (Lopes et al., 2018)

\section{A terapia de grupos e a Teoria de Grupos Operativos}

No trabalho com adolescentes, Zimerman (2010) ressalta algumas recomendações, sendo a primeira o reconhecimento da facilidade e predisposição do adolescente em anexar-se em grupos. A segunda recomendação consiste no fato do adolescente aderir melhor ao enquadre grupal, diluído entre os participantes, uma vez que a situação individual pode ser sentida com mais resistência, tendo em vista o enquadre mais condensado no indivíduo e a concentração de sentimentos de transferência. Dessa forma, 0 trabalho em grupo mostra-se o processo terapêutico com menor grau de ameaça ao indivíduo desta etapa vital, (Zimerman, 2010), sendo escolhido como téenica por diversas instituições e com resultados satisfatórios com esse público (Breitenbach \& Levandowski, 2015; Santos, Scatena, Ferriani, \& Peres, 2015; Imbacuan, Ortega, \& Herrera, 2019).

A terapia de grupos do local observado é subsidiada pela Teoria de grupos operativos desenvolvida por Enrique Pichón-Riviere. Estipula-se como grupo, um composto de pessoas unidas por condição, momento e ambiente. Os membros do grupo se conectam por uma concepção mútua que se manifesta de forma implícita ou explícita diante a tarefa e os vínculos se constituem por meio do convívio. 0 Esquema Conceitual Referencial Operativo (ECRO), desenvolvido por Pichón-Riviere (2009), foi dividido em ECRO individual, ou verticalidade e ECRO grupal, a horizontalidade. 0 principal foco está na transformação que acontece progressivamente, de forma que o grupo assume papéis estabelecidos e conduta particular frente a tarefa proposta.

A técnica de grupos operativos dispõe da Tarefa Implíita, que está na forma em que o indivíduo vive a intervenção terapêutica, ea Tarefa Explííta, que consiste no aprendizado, reconhecimento e mudança de situação. Só é possível considerar que o grupo se encontra em tarefa quando as tarefas implícita e explíita estiverem em andamento eéfundamental a resolução de pensamentos e situações estereotipadas para obtenção de mudança (Pichón-Riviere, 2009).

0 grupo operativo permite a elaboração de um projeto com a inclusão da morte como situação própria e concreta. Isto significa enfrentar problemas existenciais e conquistar adaptação ativa à realidade, com destino e ideologia de vida próprias. A Pré-Tarefa foi sistematizada como todas as atividades em que exista a presença das ansiedades básicas, que determinam a utilização de atitudes defensivas que estruturam a resistência à mudança, caracterizada por situações de impostura, que paralisa o que é proposto ao grupo (Pichón-Riviere, 2009).

A Tarefa foi descrita por Pichón como a elaboração das ansiedades básicas. Na passagem da pré-tarefa para a tarefa efetua-se um salto por soma quantitativa de insight, personificando e estabelecendo a relação com 0 outro. 0 Projeto na tarefa é o momento em que o grupo aparece com uma percepção global dos elementos que a ele pertencem e podem elaborar estratégias e táticas a fim de intervir nas situações, provocando transformação (Pichón-Riviere, 2009).

0 processo grupal é configurado por meio de uma espiral dialética conduzida conforme a demanda se transpõe. 0 objetivo maior desta prática se dá exatamente na exploração da demanda exposta. Visando analisar 0 andamento central do grupo operativo, Pichón utilizou um cone invertido como representação de um método que torne possível esta análise. No topo do cone consta 0 que está explícito no grupo, na base encontra-se o que está implíito, e entre elas percorre a espiral dialética (Pichón-Riviere, 2009). 
Atribuiu-se a esta técnica, seis vetores que viabilizam certificar-se das transformações realizadas no processo grupal. Estes vetores são: (1) Filiação e Pertença, os dois processos de identificação e elaboração grupal, manifestando o comprometimento do grupo perante a tarefa proposta; (2) Cooperação, refere-se a possibilidade dos participantes atuarem em diferentes papéis e à colaboração de cada membro do grupo para com a tarefa e demais participantes; (3) Pertinência, refere-se ao foco grupal na tarefa, a qual impostura e sabotamento da atividade dão lugar ao sentimento grupal de pertencimento e aderência a tarefa; (4) Comunicação, é o principal vetor de integração grupal e se apresenta por vias diferentes, podendo ser verbal, gestual ou através de ações comportamentais, emocionais e afetivas, possibilitando a construção de um esquema conceitual ao qual os membros do grupo se revelam operativamente; (5) Aprendizagem, aborda as alterações quantitativas responsáveis por delinear mudanças estruturais e qualitativas, implicando criatividade, elaboração de ansiedades e adaptação ativa à realidade; e (6) Telê, associada à disposição para trabalhar a tarefa grupal, demarcada por sentimentos de atração, rejeição e empatia entre os participantes, significando que todo encontro grupal se trata de um reencontro com figuras do mundo interno e da história pessoal repetidas, adaptadas e elaboradas na nova situação apresentada. Pichón ressaltou que o aparecimento destes vetores de forma progressiva faz com que todo grupo operativo seja terapêutico (Pichón-Riviere, 2009).

\section{Caracterização geral do local}

0 presente trabalho foi realizado em uma ONG localizada em Porto Alegre-RS-Brasil, que tem como objetivo o atendimento de crianças, adolescentes e adultos procedentes de famílias em vulnerabilidade social. 0 local oferece serviços nos campos educacional e da saúde nas áreas de Psicopedagogia, Psiquiatria, Psicologia, Assistência Social e Fonoaudiologia. 0 atendimento psicológico no local abrange aspectos preventivos e terapêuticos, realizado de forma individual e em grupo, sendo este último subsidiado pelas ideias de Pichón-Riviere em sua técnica de grupos operativos.

\section{Observação e identificação da demanda}

Observou-se um grupo operativo, aberto, composto por quatro adolescentes: $\mathrm{Aa}^{3}$, menina de quinze anos; Ma, menina de dezessete anos; $\mathrm{Co}$, menino de dezoito anos; e MFo, menino de quinze anos. Os quatro adolescentes e seus responsáveis assinaram o Termo de Consentimento Livre Esclarecido.

Este grupo tinha como coordenadora uma psicóloga da instituição. Um fator comum entre os participantes foi o fato de não residirem com seus genitores. Alguns participantes residiam em lares de acolhimento e outros moravam com as avós maternas. Tal característica parece relacionar-se com o observável déficit de modelos para o desenvolvimento da identidade e a confusão de papéis que desempenhavam e desejavam desempenhar, conflito que, para Erikson, essa fase implica (Erikson, 1972; Fiori, 2008).

Foi possível identificar que a demanda transpassava a fase do desenvolvimento vital em que se encontravam. Os participantes demonstraram grande preocupação com o próprio sustento e expressaram a necessidade de um trabalho remunerado. Observou-se essas necessidades nos seguintes relatos:

Ma - "Já faz dois meses que fiz dezessete, preciso trabalhar. Agora falta pouco, só mais nove meses."4

$\mathrm{Ma}$ - "Vou guardar [dinheiro] pra sair da casa. Agora que tenho dois lugares importantes pra ir e um nem tanto. Até conseguir um trabalho, preciso guardar."

Co - "Eu preciso de um trabalho pra proporcionar coisas legais pra namorada."

Os jovens que pertenciam a este grupo possuíam a urgência de prover suas necessidades pessoais, em virtude do contexto no qual vivenciavam. Com o intuito de auxiliar os adolescentes no processo de construção de identidade profissional, baseando-se na singularidade e no desejo pessoal, pensou-se em uma atividade que permitisse reflexão, estimulando 0 autoconhecimento e enfatizando as potencialidades dos participantes. A partir disso, elaborou-se uma forma de auxiliar primordialmente 0 ingresso e incorporação dos participantes na tarefa grupal: usando o Roleplaying Game (RPG), um jogo de equipe a qual o participante denominado como Mestre conduz uma narrativa viva e imaginada em que os demais participantes percorrerão uma aventura que envolve interpretação de papéis, regras, rolar de dados, atividades de competição e atividades que demandam escolhas.

\section{A intervenção}

Disponibilizou-se aos participantes papel, canetas coloridas, lápis de cor, tesoura, cola e revistas para que utilizassem a imaginação para a confecção de um avatar. Cada participante criou um avatar que o representasse na realização do RPG. 0 grupo construiu seus avatares com base em suas características pessoais, identificando assim as suas potencialidades. Neste encontro foi possível observar que os adolescentes ainda demonstravam resistência no ingresso à tarefa grupal. Conforme as falas de Aa, Co e MFo.

Aa - "Ah, eu não quero fazer."

Co - "Não dá para deixar para outra semana?"

MFo - "Achei mais ou menos o meu personagem."

Apesar da resistência, o grupo foi ingressando na tarefa, porém ainda era perceptível a presença dos medos básicos, determinando a utilização de atitudes defensivas. Esse funcionamento mostrava que o grupo ainda se encontrava em situação de pré-tarefa, manifestado nas falas:

Ma - "Tá, deixa eu ver se encontro alguém que seja bonita como eu."

Aa - "Eu não quero fazer isso. Tem alguém de esporte nessa revista? Achei, combina comigo"

Co - "Achei, vai ser esse muçulmano mesmo. Até parece eu velho"

Ma - "Eu sou um casal, nada romântico, sem coisa melosinha."

A resistência apresentada na confecção dos avatares foi confirmada pela ausência das duas meninas na sessão seguinte, quando iniciou o jogo de RPG. Em virtude do grupo ser aberto, a tarefa proposta foi realizada com

\footnotetext{
3 Para este estudo, cada participante está representado pela letra inicial do seu nome em maiúsculo, seguido pelo artigo "a" para aquelas que se identificavam como meninas e o artigo "o" para aqueles que se identificavam como meninos.

4 Todas as vinhetas apresentadas são literais e não tiveram correção ortográfica ou gramatical.
} 
os participantes presentes. 0 jogo foi confeccionado e narrado pelo Mestre, estagiário de Psicologia convidado a participar da intervenção, com base nas sínteses grupais, relatos de observação e identificação da demanda do grupo. Os participantes foram apresentados ao conceito do RPG e a psicóloga da instituição, coordenadora do grupo, fez o papel de observadora durante essa tarefa. Para dar início ao jogo, cada participante jogou o dado de vinte lados definindo a pontuação que representava o nível de habilidade com que iniciaria o jogo. Em seguida, pediu-se que os participantes contassem uma breve história de seus avatares, por exemplo:

MFo - "Ele é jogador de futebol, ele é pobre e tem trinta e seis anos."

Co - "Forte, esperto, gosta de montar estratégia, tem quarenta anos e é muçulmano."

A história do jogo começou com os avatares em uma praça e os participantes escolheram iniciar a história jogando futebol juntos. As luzes da praça se desligaram e o auto falante avisou que haveria uma quarentena militar em que todos os indivíduos que estivessem na rua seriam presos temporariamente. A primeira decisão desta narrativa era fugir ou tentar falar com os militares.

\section{Co - "Dialogar, se eu correr eles vem atrás." \\ MFo - "Fugir, não quero ser preso."}

Os participantes jogaram o dado da Sorte para dar continuidade aos acontecimentos da história. Se tirassem no dado um número que significasse sorte tinham êxito em suas atitudes no jogo. Caso os participantes não tirassem os números referentes à sorte, o desfecho da história mudava. A segunda decisão estava relacionada ao fato dos participantes optarem por se dividir na história do jogo.

Mestre -"MFo, deixaria Co preso ou o ajudaria?

MFo - "Deixaria ele preso e me esconderia."

Mestre - "Então tu está escondido embaixo de uma escadaria no qual tu consegue ver tudo que está acontecendo, e um homem pede para se esconder contigo, o que tu faria?"

\section{MFo - "Sai daqui se não vou te bater."}

Mestre - "Este personagem que quer se esconder contigo é um advogado e te diz que sabe como se livrar disto."

MFo - "Pode se esconder. Mas não faça nada senão eu vou te bater. Não dá pra fazer barulho também, se não vão nos achar."

MFo demonstrou sua realidade, revelando não sentir confiança ao ficar sozinho com outros homens. MFo havia sofrido abusos sexuais na infância e nem durante a brincadeira de fantasia conseguiu sentir-se seguro na circunstância de ficar sozinho com um homem, o que justifica a sua fala anterior.

A próxima decisão foi do MFo, pois o avatar dele e o advogado sofreram um acidente de carro. Neste momento MF. deveria tomar uma decisão de como agir perante 0 acidente:

MFo - "Eu ajudo ele, mas sigo sozinho, não vou carregar."

MFo e Co demonstraram que realmente estavam inseridos na tarefa, tomando decisões que demandavam pensamento estratégico.

Co - "Olha, por ponto de vista estratégico, fugir é pior. 0 jeito é continuar prestando atenção na palestra e esperar ir preso."
MFo - "A estratégia é procurar o caminho, se falar com eles podem me prender."

Os participantes se demonstraram pertencentes ao jogo e a dupla passou a valorizar 0 trabalho em equipe.

MFo - "Andar junto."

Co - "Quanto mais gente melhor."

MFo - "Dois pensam mais."

Os participantes tiraram a sorte nos dados. C conseguiu o número de sorte, porém MF deu azar.

MFo- "Ah, já tamo ferrado."

Co - "Ah, depois de tanto trabalho." Deixou-se claro que os participantes não seriam julgados pelas suas escolhas e que podiam agir conforme fariam na vida. Neste momento foi observável que os participantes agiram sem contenção de impulsos e sentiram a necessidade de desculpar suas atitudes.

Co -"Meter o pé na porta [...] Só queremos dialogar, desculpa a atitude [...] Eu puxo a arma e coloco na cara dele. No mínimo 300. Engatilho a arma e atiro."

MFo - "Mas era pra deixar ele vivo. Todo dinheiro é nosso agora."

Perguntou-se para onde os participantes iam neste momento, já que 0 advogado não havia dito o destino e o político estava morto. MFo chamou a atenção de Co por decidir matar o político.

MFo - "Eu falei pra deixar ele vivo [...] E agora, tentar a sorte de novo?"

0 jogo finalizou com os participantes no mesmo lugar em que começaram. Com base no desfecho do jogo, conversou-se com os participantes sobre as decisões tomadas e o que elas implicavam, um movimento que abriu espaço para que os participantes expressassem a aderência à tarefa e sentimentos sobre o encontro.

MFo - "Nossa, muito legal. Dá vontade de jogar mais. 0 tempo passou voando."

Co - "Nunca fiquei com tanta vontade de não ir embora da terapia."

\section{Resultados e discussão}

0 presente trabalho confirmou que o enquadre grupal é bastante apropriado na escolha de terapia para adolescentes pelo fato de a ansiedade diluir-se entre os membros do grupo, colaborando com o processo terapêutico, tendo em vista a resistência do indivíduo desta fase vital no enquadre mais condensado (Zimerman, 2010).

A montagem do avatar contou com a participação de quatro membros deste grupo operativo e observou-se que os participantes expressaram resistência para ingresso nessa tarefa, configurando o grupo em estado de pré-tarefa. (Pichón-Riviere, 2009). A resistência apresentada na confecção dos avatares foi confirmada pela ausência das duas meninas na sessão seguinte, quando haveria o jogo de RPG propriamente dito.

Durante a montagem do avatar também se identificou as potencialidades dos participantes, bem como os modelos que classificam como de êxito, assim possibilitando que tarefa implícita e explícita ocorressem simultaneamente, 
fazendo com que o grupo desse um salto quantitativo, estipulado como transição de pré-tarefa para tarefa. Os participantes tiveram os seis vetores identificados durante a espiral dialética que ocorreu perante o tema proposto. Essa intervenção conseguiu abordar a elaboração das ansiedades básicas dos participantes, que atingiram, ao longo do jogo os vetores: Filiação, Pertença e Comunicação, ao ingressarem na atividade proposta; e utilizaram durante 0 jogo os vetores: Cooperação e Telê, ao tomarem suas decisões perante o jogo proposto (Pichón-Riviere, 2009).

Os adolescentes demonstraram que algumas características mudaram em curto espaço de tempo, atitude que Erikson referiu-se como principal marco desse momento do ciclo vital. 0 adolescente busca 0 autoconhecimento e reconhecimento do self transitando pelas opções possíveis para então identificar-se (Erikson, 1972; Fiori, 2008, Lopes et al., 2018), bem como observado no Roleplaying Game. Observou-se que o adolescente ingressa com facilidade na tarefa quando se sente acolhido e parte do grupo, sentimento denominado no processo grupal como Pertença, vetor que possibilita a execução da prática, fazendo a tarefa grupal possível (Pichón-Riviere, 2009), conforme observado neste relato de experiência.

Foi possível observar na intervenção os participantes atuando nos níveis descritos por Erickson, principalmente o (2) Identidade Profissional e o (3) Identidade Ideológica. Por meio da realização profissional o indivíduo se sentirá competente para integrar-se como membro ativo e produtivo na sociedade. Assim, o indivíduo estará seguro não só do que é, mas, do que continuará sendo, permanentemente se reconstruindo internamente, para acompanhar a reorganização do mundo e assumir uma opinião. Erikson enfatizou que estando seguro do que é, o indivíduo estará apto para as próximas etapas do desenvolvimento e se sentirá seguro do que continuará sendo (Fiori, 2008).

Os participantes desenvolveram durante o jogo o Projeto na tarefa. 0 Projeto aconteceu no momento em que a dupla, Co e MFo, começou a apresentar uma percepção global dos elementos do jogo, o que possibilitou instrumentalizá-Ios com um contato com a realidade, no qual foi possível sua colocação como sujeito ativo. A elaboração de táticas e estratégias interveio nas situações provocando transformações e aprendizagem que vão além do jogo no qual eles puderam elaborar sua fantasia tendo a certeza que não seriam julgados (Pichón-Riviere, 2009) e onde o adolescente passa a perceber-se como protagonista da própria mudança (Santos et al., 2015).

Esta experiência revelou a importância da motivação para que o adolescente execute as tarefas de sua responsabilidade com êxito e satisfação. Lacerda e Lacerda (1998), citaram em sua obra e Gardner (2001), ressaltou em sua teoria, que ao enfatizar as potencialidades do indivíduo, o desenvolvimento das atividades por ele realizadas torna-se de qualidade mais elevada.

Evidenciou-se que o uso do Roleplaying Game se apresentou como uma ferramenta facilitadora para 0 alcance da tarefa desse grupo operativo por ser um jogo que envolve criação de um avatar, que consequentemente favoreceu a projeção e identificação dos participantes bem como a revelação das fantasias universais, fundamentais para que o processo de mudança aconteça. Além disso, o RPG promoveu a elaboração das ansiedades básicas e auxiliou no processo de tomada de decisão dos participantes, agindo como uma ferramenta no processo terapêutico, bem como no processo de construção da identidade. Enfim, os participantes acolheram a tarefa de forma significativa e esta intervenção conseguiu atingir os objetivos propostos.

\section{Considerações finais}

A prática realizada por estagiários na área clínica muitas vezes traz abertura para novas ferramentas e "alinhavos" teóricos acerca de atividades usualmente realizadas nos locais de estágio de Psicologia. Assim, o espaço para divulgação, em caráter científico, de relatos de experiência é de grande valia para a classe profissional, principalmente para possibilidades de aplicação na saúde pública.

Mais estudos e relatos de intervenções utilizando grupos operativos são importantes, uma vez que a grupoterapia é uma das formas mais utilizadas nas políticas públicas de saúde. E sem dúvidas faz-se necessário mais aplicações e investigações do uso do RPG como ferramenta a ser utilizada no contexto clínico para seguir confirmando o que o presente trabalho apresenta. Por sua ludicidade, acreditamos que se mostrará uma ferramenta útil em diversas experiências da clínica psicológica.

\section{Referências}

Breitenbach, I. M. S., \& Levandowski, D. C. (2015). Grupo operativo com adolescentes que vivenciam a ausência paterna temporária: relato de experiência. Contextos Clínicos, 8(2), 153-164.

Calligaris, C. (2009) A Adolescência. Coleção Folha Explícita, (2a ed). São Paulo: Publifolha

Erikson, E. H. (1972). Infância e sociedade. Rio de Janeiro: Zahar.

Santos, M. A., Scatena, L., Ferriani, M. D. G. C., \& Peres, R. S. (2015). Grupo operativo com adolescentes em um núcleo da assistência social: a questão da identidade de gênero. Vínculo-Revista do NESME, 12(1), 51-58.

Imbacuan, G. L. R., Ortega, H. F. L., \& Herrera, J. D. G. (2019). Habilidades psicosociales en niños y adolescentes como herramientas para una vida productiva. Boletín Informativo (E), 6(2), 28-35. Recuperado a partir de http://editorial.umariana.edu.co/revistas/index.php/BoletinInformativoCEl/article/view/1986

Fiori, W. (2008) Desenvolvimento emocional. In: Rappaport, C.R; Fiori, W; Davis, C. Teorias do desenvolvimento, Vol 4: A idade escolar e a adolescência. São Paulo: Editora Pedagógica Universitária.

Gardner, H. (2001) Inteligência: Um Conceito Revisão. Rio de Janeiro: Objetiva Lacerda, C. A. 0. P; Lacerda, M. P. (1998) Adolescência: Problema, mito ou desafio. Rio de Janeiro: Editora Vozes.

Lopes, A. A., Famoseli, A. F. de 0., Macedo, E. H. S., Figueiredo. E. A., Acácio, K. H. P. (2018). Reflexões sobre a relação: Adolescência, família e escolha profissional. Caderno de graduação ciências humanas e sociais UNIT Sergipe, 5(1), 179.

Pichón-Riviere, E. (2009) OProcesso Grupal, (8a ed). São Paulo:WMF Martins Fontes.

Zimerman, D. E. (2010) Fundamentos básicos das grupoterapias, (2a ed). Porto Alegre: Artmed. 